\title{
Predictors of depression, anxiety and stress among remote workers during the COVID-19 pandemic
}

\author{
Erman Şentürk $^{\mathrm{a}, *}$, Eser Sağaltıca ${ }^{\mathrm{a}}$, Bahadır Geniş ${ }^{\mathrm{b}}$ and Ömür Günday Toker ${ }^{\mathrm{a}}$ \\ ${ }^{a}$ Department of Psychiatry, Bagcilar Training and Research Hospital, University of Health Sciences, Istanbul, \\ Turkey \\ ${ }^{\mathrm{b}}$ Department of Psychiatry, Kocaeli University Faculty of Medicine, Kocaeli, Turkey
}

Received 28 January 2021

Accepted 13 May 2021

\begin{abstract}
.
BACKGROUND: The COVID-19 pandemic has had a massive impact on work and home life, changing all daily routines of remote workers. It is extremely important to figure out some changes in home and work life that may affect the mental health of remote workers more.

OBJECTIVES: The first aim of the study was to investigate the predictors of depression, anxiety, and stress among first-time remote workers during the COVID-19 pandemic. The second aim was to explore sex differences regarding work and home life during the COVID-19 pandemic.

METHODS: The sample consisted of 459 participants who have been working from home for the first time during the COVID-19 pandemic. An online survey used included questions relating to sociodemographic characteristics, changes in work and home life, Depression Anxiety Stress Questionnaire-Short Form, Jenkins Sleep Scale, and Leisure-Time Exercise Questionnaire.

RESULTS: The prevalence of depression, anxiety, and stress was $17.9 \%, 19.6 \%$, and $19.6 \%$ of the participants, respectively. Poor sleep quality, trouble focusing at work, being female, workplace loneliness, low levels of control over working hours, and low levels of physical activity were predictors of depression. Poor sleep quality, increased workload, and being female were predictors of anxiety. Poor sleep quality, trouble focusing at work, being female, financial concern, and workplace loneliness were predictors of stress. It was observed a higher increase in both housework and working hours during the COVID-19 pandemic in women.

CONCLUSION: Determining the variables that can affect the mental health of remote workers is highly important for timely psychological intervention.
\end{abstract}

Keywords: Working from home, remote working, teleworking, Mental health, gender inequality

*Address for correspondence: Erman Şentürk, Department of Psychiatry, Bagcilar Training and Research Hospital, University of Health Sciences, Istanbul, Turkey. Tel.: +90 2124405424; E-mail: erman.senturk@hotmail.com. ORCID: orcid.org/00000001-9208-7905

\section{Introduction}

The COVID-19 pandemic has in general altered the dynamics of daily life. On the one hand, COVID-19 has threatened the physical health of people around the world. On the other hand, it has induced a large number of people to suffer from mental health problems due to stressors such as physical distance, 
self-isolation, fear, and financial concerns [1]. This health crisis has led to unprecedented impacts on workplace practices. Millions of employees from different countries shifted to working from home (WFH) in a short time. During the COVID-19 pandemic, WFH has become crucial for many companies and governments since it appears the first option to both continue working and reducing the spread of the virus [2]. Due to the uncertainty about the duration of the pandemic and the possible future waves of contagion, companies have begun to take into account WFH as a "new normal" way of working [3].

WFH has played a key role in reducing the spread of COVID-19. However, this mandatory and sudden shift to WFH has caught employees unprepared to adjust to the alteration. Contrary to working in the office, many employees have experienced significant difficulties due to overtime for dealing with household chores and childcare. WFH is new for many workers, so the change of workplace can yield a number of distractions. Many distractions can arise such as children playing, pets, and neighbors making noise [4]. Data from several studies suggested that employees who work from home tended to work longer hours than employees at the offices $[4,5]$. Increased workloads, overtime, and irregular working hours have led to the deterioration of the daily routines of employees. Overtime may induce negative changes in the biological rhythm, which is extremely important for mental health [6]. WFH has completely reshaped the traditional 9-to-5 working style and blurred the lines between home and office [7]. This blurred line of the boundary between professional and personal life has made many employees not able to disconnect from work and work-related issues in their leisure time [8]. Research in this area showed that employees who could detach from work during off-hours felt more satisfied [9-12].

The overwhelming deficiency of human interaction has taken its toll on mental health during the COVID-19 pandemic. People lose the vast majority of their spontaneous interactions with others by WFH. WFH may trigger feelings of loneliness due to a longer-term disconnection from social interactions at the workplace [13]. Loneliness was considered to have a negative effect on mental health and well-being [14].

It is inevitable that such changing conditions have a major impact on nighttime sleep as well. Adequate sleep duration, quality, and timing are key components for coping with life-threatening events such as the COVID-19 pandemic [15]. The blurry line between personal and professional life, excessive coffee consumption, late-night screen time, overtime, and procrastination may cause an increase in the incidence of sleep disorders. Several studies found that the prevalence of sleep disorders had increased during the COVID-19 pandemic $[16,17]$. In the context of the disruption of daily routines and excessive screen time, the COVID-19 pandemic can cause sleep disorders as well as health risks such as increased weight and sedentary life. Sleep plays a fundamental role in regulating and functioning emotion. Even a single night of sleep deprivation may cause noteworthy mood disturbances. Prolonged sleep loss increases the risks of long-term adverse consequences for mental health $[18,19]$.

During remote working, secondary to long working hours may significantly increase sedentary time, particularly screen time. Lower levels of participation in activities outside of the home due to COVID19 restrictions can further increase sedentary life. A sedentary lifestyle or increased screen time is a major global public health issue due to its known negative effects on both physical and mental health $[20,21]$.

The division of labor between men and women during WFH is closely related to established social and cultural gender roles. Gender roles continue to tie fatherhood primarily to full-time employment and motherhood to time-consuming child-centered caregiving and housework [22-24]. Unbalanced division of labor may exacerbate gender inequality in household chores and childcare, which make women's working life more difficult.

Prior to the COVID-19 pandemic, WFH was not a very common way of working in Turkey. Millions of employees who have no previous experience of working outside the office have experienced WFH for the first time. Moreover, the uncertainty about when the pandemic will end and possible new COVID-19 contagion waves lead to predictions that WFH may become long-term or even permanent [25]. Although various studies have been carried out on WFH, there are only a few studies investigating the relationships between changes in work and home life and mental health of remote workers during the COVID-19 pandemic. Given the psychological effects of the rapidly changing dynamics and the paucity of current data, the present study was designed and conducted to investigate the predictors of depression, anxiety, and stress among first-time remote workers during the COVID-19 pandemic. The secondary aim of this research was to explore changes in work and home life in terms of sex differences. 


\section{Method}

\subsection{Study setting and sample}

The current study combined a snowball sampling technique with a cross-sectional, web-based survey and recruited 459 remote workers who began to work from home for the first time after the COVID-19 pandemic has been declared. The COVID-19 pandemic period is a time when it is difficult to reach participants due to restrictions in every aspects of life and the risk of virus transmission. In cases where it is difficult to reach the universe, non-probability sampling methods are used to reach the participants [26]. Therefore, the snowball sampling method, which is a non-probability (purposeful) sampling method was used in this study. Survey and informative forms (names of researchers and their institutions, scope and purpose of the study, participation criteria, data privacy commitment form, survey instruments) were transferred to an online questionnaire. All responses were anonymous and no personally identifiable information was requested. Primary inclusion criteria for the participants were no remote working experience prior to the COVID-19 pandemic, WFH for at least six months after the COVID-19 pandemic declaration, WFH at the time of the questionnaire, graduation from the university.

\subsection{Measurements}

Sociodemographic characteristics included age, sex, job, parental status, and educational level.

After the participants started WFH, the changes in work and home life were evaluated through eight questions. The first three questions were about changes in time spent on dealing with daily work time, household chores, childcare. Participants were requested to mark three items on a nine-point scale related to changes in time spent on dealing with daily work time, household chores, and childcare $(1=4$ hours or more decreased, $5=$ not changed, $9=4$ hours or more increased). The fourth question was about the change in the workload of the participants (utilized a 5-point scale; $1=$ significantly decreased, $3=$ not changed, $5=$ significantly increased). The fifth question was about the participants' control over their working hours (high levels of control over working hours, moderate levels of control over working hours, low levels of control over working hours). The sixth question was about concentration and distraction of the participants. This question was measured with two items: "I am distracted while working (e.g., noisy neighbors, pets, and child who need attention)" and "Focus on work is taking a longer time than before". Responses were given on a 5-point scale ranging from 1 (never) to 5 (always). The seventh question was related to workplace loneliness. Participants were asked about the mood effects of being physically away from colleagues or teammates. Responses were given on a 5-point scale ranging from 1 (strongly negative) to 5 (strongly positive). The eighth question assessed the current financial state and financial concern levels of participants. The financial condition of participants was measured with two items that reflect the current and the expected financial situation. Questions were "How would you rate your financial situation in these days?" and "What is your financial expectation six months from now?". Responses were given on an 11-point scale ranging from 0 (the worst financial situation) to 10 (the best financial situation).

Depression Anxiety Stress Questionnaire - Short Form (DASS-21) [27] is a self-report questionnaire in which participants rate the frequency and severity of depression, anxiety, and stress. The participants were asked to mark how often they experienced the emotions and situations mentioned during the past week. As measured by the DASS-21, depression subdimension assesses dysphoria, anhedonia, lack of interest, and low self-esteem; anxiety sub-dimension assesses subjective experience of the anxiety effect, autonomic arousal, skeletal muscle effects, and situational anxiety; and stress sub-dimension assesses irritability, being overactive, impatience, tension, and persistent arousal. DASS-21 includes twenty one questions and three components of depression (7 questions), anxiety (7 questions), and stress (7 questions). Questionnaire scoring is a four-point Likert scale $(0=$ does not apply to me at all, $3=$ applies to me very much or most of the time). The final result is obtained by summing the scores of the items on each subscale. The depression score results are classified as normal (0-9), mild depression (10-12), moderate depression (13-20), severe depression (21-42). The anxiety score results are classified as normal (0-6), mild anxiety (7-9), moderate anxiety (10-14), severe anxiety (15-42). The stress score results are classified as normal (0-10), mild stress (11-18), moderate stress (19-26), severe stress (27-42). The Turkish validity and reliability of DASS-21 has been demonstrated in previous studies [28, 29]. In current study, Cronbach's alpha was 0.94 for DASS-21, 0.88 for depression, 0.82 for anxiety, and 0.88 for stress, indicating a good internal consistency for each subscale. 
Jenkins Sleep Scale (JSS) [30] was used to assess subjective sleep quality. JSS was designed to measure common sleep problems in the clinical population and then used for the general population as well [31]. It comprises 4 items that assess in the past four weeks (a) trouble falling asleep, (b) trouble staying asleep, (c) wake up several times/night, and (d) wake up feeling tired. Each item is rated on a 6-point Likert scale (not at all $=0,1-3$ days $=1,4-7$ days $=2,8-14$ days $=3,15-21$ days $=4,22-28$ days $=5$ ). The total score is ranging from 0 to 20 , showing poorer sleep quality as it increases. In the validity and reliability of the Turkish version of the JSS, Cronbach's alpha was found 0.862 [32]. In current study, this value was 0.82 .

The Leisure-Time Exercise Questionnaire (LTEQ) [33] consists of three items assessing the frequency of mild (minimal effort), moderate (not exhausting), and strenuous (heart beating rapidly) exercise. LTEQ was about assessing the physical activity that the participants engage in their leisure time. Participants were asked to rate how often they engage in leisure-time exercise during a typical week for at least $20 \mathrm{~min}$. The overall score was computed as followed: $(3 \times$ mild $)+(5 \times$ moderate $)+(9 \times$ strenuous $)$. In the validity and reliability of the Turkish version of the LTEQ, Cronbach's alpha was found 0.94 [34].

\subsection{Data analysis}

Data was analyzed by using SPSS Statistics 23.0 software package. Descriptive statistics were expressed using frequency, percentage, mean, and standard deviation. Since the skewness and kurtosis values of the numerical variables vary between \pm 2 , it is assumed that the data show normal distribution [35]. Therefore, parametric tests were used in the analysis. Differences between numerical variables were compared using Independent Samples $T$-Test. Multiple linear regression models were used with enter method to investigate potentially predictive factors for the sub-dimensions of DASS-21 (depression, anxiety, and stress) in the employees who work from home for the first time. The variables were determined as relevant variables to be considered in analysis, in accordance with clinical experience and literature review [36-39]. Three main factors used for all the models are as follows: The first factor was sociodemographic characteristics including sex, age, educational status, working organizations, and having a child. The second factor was possible changes in work and home life during WFH including changes in time spent on household chores and childcare, changes in daily working hours and workload, control over working hours, distractions and focusing, financial state and workplace loneliness. The third factor was body wellness including sleep quality and leisure-time exercise. In these regression analyzes, Durbin Watson values were found to be 1.671 for the depression sub-dimension, 1.952 for the anxiety subdimension and 1.649 for the stress sub-dimension. In the regression analyzes, Variance Inflation Factors (VIF) values are between $0.310-0.959$, while tolerance values are between 1.043-3.222. Accordingly, it was seen that the models created based on the norms accepted in the literature do not have multicollinearity and autocorrelation problems [40]. Internal reliability coefficients (Cronbach's alpha) were used to evaluate the internal consistency or reliability of a data. $p<0.05$ level was considered significant for statistical analysis.

\subsection{Legal approvals}

Data was collected via an online questionnaire from October 25 to December 24, 2020, during the lockdown of the COVID-19 pandemic. Ethical approval had previously been granted by the Ethics Board of Bağcllar Training and Research Hospital, İstanbul (Document No. 2020.10.2.06.167).

\section{Results}

The sociodemographic characteristics of the sample are shown in Table 1. Out of 459 respondents, 254 $(55.3 \%)$ were male and $205(44.7 \%)$ were female. The age of the participants ranged from 24 to 60 years $(\mathrm{M}=35.64, \mathrm{SD}=6.84)$ and mean age was $35.64 \pm 6.84$. As far as education level is concerned, $318(69.3 \%)$ participants were graduated from university, while $141(30.7 \%)$ were postgraduate degree holders. Of the total, 228 (49.7\%) of the participants had a child. Considering the occupations of participants, 100 (21.8\%) were software developers, $79(17.2 \%)$ were pharmaceutical industry employees, $74(16.1 \%)$ were sales and marketing employees, 67 (14.6\%) were bank employees, 29 (6.3\%) were public officers, $29(6.3 \%)$ were engineer, 24 (5.2\%) were textile workers, $11(2.4 \%)$ were airlines workers, $11(2.4 \%)$ were insurance workers, $9(2.0 \%)$ were teachers, $9(2.0 \%)$ were food workers, $8(1.7 \%)$ were logistics workers, $6(1.3 \%)$ were human resources workers, $3(0.7 \%)$ were tourism professionals. 
Table 1

Sociodemographic characteristics

\begin{tabular}{|c|c|c|c|}
\hline & & $\begin{array}{c}\text { Mean } \\
n\end{array}$ & $\begin{array}{c}\text { Standard } \\
\text { Deviation } \\
\%\end{array}$ \\
\hline Age & & 35.64 & 6.84 \\
\hline \multirow[t]{2}{*}{ Sex } & Male & 254 & 55.3 \\
\hline & Female & 205 & 44.7 \\
\hline \multirow{2}{*}{$\begin{array}{l}\text { Educational } \\
\text { status }\end{array}$} & University & 318 & 69.3 \\
\hline & Postgraduate degree & 141 & 30.7 \\
\hline \multirow{2}{*}{$\begin{array}{l}\text { Working } \\
\text { organizations }\end{array}$} & Public sector & 69 & 15.0 \\
\hline & Private sector & 390 & 85.0 \\
\hline \multirow[t]{14}{*}{ Occupations } & Software developers & 100 & 21.8 \\
\hline & Pharmaceutical industry & 79 & 17.2 \\
\hline & Sales and marketing & 74 & 16.1 \\
\hline & Bank & 67 & 14.6 \\
\hline & $\begin{array}{l}\text { Public services or } \\
\text { administration }\end{array}$ & 29 & 6.3 \\
\hline & Engineer & 29 & 6.3 \\
\hline & Textile & 24 & 5.2 \\
\hline & Airlines & 11 & 2.4 \\
\hline & Insurance & 11 & 2.4 \\
\hline & Teacher & 9 & 2.0 \\
\hline & Food & 9 & 2.0 \\
\hline & Logistics & 8 & 1.7 \\
\hline & $\begin{array}{l}\text { Recruitment or Human } \\
\text { resources }\end{array}$ & 6 & 1.3 \\
\hline & Tourism & 3 & 0.7 \\
\hline \multirow[t]{2}{*}{ Having a child } & No & 231 & 50.3 \\
\hline & Yes & 228 & 49.7 \\
\hline
\end{tabular}

Variables related to changes in work and home life are in Table 2. It was found that the spending time on housework and childcare increased on average in the sample (6.04 $\pm 1.80,6.15 \pm 1.73$, respectively). $42.7 \%$ of the participants declared that the workload related to their work did not change, while $35.1 \%$ declared that it increased. Just over half $(50.3 \%)$ of those surveyed reported that they had moderate levels of control over working hours, $23.7 \%$ of them had low levels of control over working hours. $27.5 \%$ of those who were participants indicated that time for focus on working often took a longer time than before and $5.2 \%$ of them indicated that it always took longer time. Almost one-third of the participants $(33.8 \%)$ indicated distraction sometimes while working due to external factors. Rates of those who often and always exposed to this trouble were $21.8 \%$ and $4.1 \%$, respectively. While the participants evaluated their current financial state at a moderate level $(5.83 \pm 2.23)$, they considered that their financial state would decrease partially $(5.59 \pm 2.21) 6$ months later. When asked whether the effects of being physically away from colleagues or teammates, $51 \%$ of the respondents reported no effect, $30.7 \%$ negative effect, $2.8 \%$ strongly negative effect.
Prevalence of depression, anxiety and stress in the sample is shown in Table 3. According to the DASS21 scale, $17.9 \%$ of the participants had various levels of depression, which were mild depression at $10.7 \%$, moderate depression at $7.0 \%$, and severe depression at $0.2 \%$. Various levels of anxiety were detected in $19.6 \%$ of participants. The frequency of mild anxiety was $12.9 \%$, moderate anxiety $6.1 \%$, severe anxiety $0.6 \%$. Various levels of stress were detected in $19.6 \%$ of the participants. The frequency of mild stress was $19.4 \%$, and moderate stress was $0.2 \%$.

A comparison of factors related to changes in work and home life by sex is shown in Table 4. During the WFH period, women declared that their time spending on household chores $(p=0.001)$, working hours $(p=0.006)$, workload $(p=0.012)$ increased more than men, and they were more distracted while working $(p=0.009)$.

Sub-dimensions of the DASS-21 questionnaire by multiple linear regression analysis is shown in Table 5. Models created for Depression, Anxiety, and Stress were significant ( $p<0.001$ for each), and these models explained $40 \%, 31 \%$, and $37 \%$ of the variance, respectively. Poor sleep quality $(\beta=0.378$, $p<0.001)$, trouble focusing at work $(\beta=0.138$, $p<0.001)$, being female $(\beta=0.137, p=0.001)$, workplace loneliness $(\beta=-0.133, p=0.001)$, low levels of control over working hours $(\beta=0.094, p=0.020)$ and low levels of leisure-time physical activity $(\beta=-0.094, p=0.012)$ were predictors of depression respectively. Significant predictors of anxiety included poor sleep quality $(\beta=0.373, p<0.001)$, increased workload $(\beta=0.117, p=0.019)$, being female $(\beta=0.097, p=0.023)$ respectively. Significant predictors of stress included poor sleep quality $(\beta=0.324, p<0.001)$, trouble focusing at work $(\beta=0.165, p<0.001)$, being female $(\beta=0.155$, $p<0.001)$, financial concern $(\beta=-0.100, p=0.040)$ and workplace loneliness $(\beta=-0.095, p=0.019)$ respectively.

\section{Discussion}

This study set out to investigate the predictors for depression, anxiety, and stress of first-time remote workers during the COVID-19 pandemic. Stressful life events such as poor financial state, job loss, getting divorced, natural disasters, death of a loved one, illness are prominent changes in an individual's life that can challenge the potential to adapt. Such changes may cause psychological distress by 
Table 2

Variables related to changes in work and home life

\begin{tabular}{|c|c|c|c|}
\hline \multicolumn{2}{|c|}{ Changes in work and home life during working from home } & $\mathrm{n} / \mathrm{mean}$ & $\% / \mathrm{SD}$ \\
\hline \multicolumn{2}{|c|}{$\begin{array}{l}\text { Changes in time spent on household chores ( } 1=4 \text { hours or more decreased, } 5=\text { not changed, } 9=4 \text { hours or more } \\
\text { increased) }\end{array}$} & 6.04 & 1.80 \\
\hline \multicolumn{2}{|c|}{ Changes in time spent on childcare ( $1=4$ hours or more decreased, $5=$ not changed, $9=4$ hours or more increased) } & 6.15 & 1.73 \\
\hline \multicolumn{2}{|c|}{ Changes in daily working hours $(1=4$ hours or more decreased, $5=$ not changed, $9=4$ hours or more increased $)$} & 5.24 & 2.52 \\
\hline \multirow[t]{6}{*}{ Changes in workload } & (1) Significantly decreased & 16 & 3.5 \\
\hline & (2) Decreased & 43 & 9.4 \\
\hline & (3) Not changed & 196 & 42.7 \\
\hline & (4) Increased & 161 & 35.1 \\
\hline & (5) Significantly increased & 43 & 9.4 \\
\hline & mean $\pm \mathrm{SD}$ & 3.37 & 0.90 \\
\hline \multirow[t]{3}{*}{ Control over working hours } & Low levels of control over working hours & 121 & 26.4 \\
\hline & Moderate levels of control over working hours & 231 & 50.3 \\
\hline & High levels of control over working hours & 107 & 23.3 \\
\hline \multirow[t]{6}{*}{ Distractions while working } & (1) Never & 106 & 23.1 \\
\hline & (2) Rarely & 79 & 17.2 \\
\hline & (3) Sometimes & 155 & 33.8 \\
\hline & (4) Often & 100 & 21.8 \\
\hline & (5) Always & 19 & 4.1 \\
\hline & mean $\pm \mathrm{SD}$ & 2.66 & 1.14 \\
\hline \multirow[t]{6}{*}{ Trouble focusing at work } & (1) Never & 76 & 16.6 \\
\hline & (2) Rarely & 89 & 19.4 \\
\hline & (3) Sometimes & 144 & 31.4 \\
\hline & (4) Often & 126 & 27.5 \\
\hline & (5) Always & 24 & 5.2 \\
\hline & mean $\pm \mathrm{SD}$ & 2.85 & 1.14 \\
\hline \multicolumn{4}{|c|}{$(0=$ The worst financial state, $10=$ The best financial state $)$} \\
\hline \multicolumn{4}{|c|}{$(0=$ The worst financial state, $10=$ The best financial state $)$} \\
\hline \multirow[t]{6}{*}{ Effect of workplace loneliness } & (1) Strongly negative & 13 & 2.8 \\
\hline & (2) Negative & 141 & 30.7 \\
\hline & (3) Neutral & 234 & 51.0 \\
\hline & (4) Positive & 55 & 12.0 \\
\hline & (5) Strongly positive & 16 & 3.5 \\
\hline & mean $\pm \mathrm{SD}$ & 2.83 & 0.80 \\
\hline
\end{tabular}

$\mathrm{n}$ : Number of participants; SD: Standard Deviation.

Table 3

Prevalence of depression, anxiety and stress

\begin{tabular}{lccc}
\hline $\begin{array}{l}\text { Severity of } \\
\text { disorder }\end{array}$ & Depression & Anxiety & Stress \\
\hline Normal & $377(82.1 \%)$ & $369(80.4 \%)$ & $369(80.4)$ \\
Mild & $49(10.7 \%)$ & $59(12.9 \%)$ & $89(19.4 \%)$ \\
Moderate & $32(7.0 \%)$ & $28(6.1 \%)$ & $1(0.2 \%)$ \\
Severe & $1(0.2 \%)$ & $3(0.6 \%)$ & - \\
\hline
\end{tabular}

exceeding the mental capacity of individuals. Stress, anxiety, and depression were used in this study to measure mental health. Depression is a mood disorder that involves a low mood and a loss of interest in activities. Anxiety is a reaction to stress, with feelings of worry, nervousness, irritability or unease. Stress is a feeling of emotional or physical tension. It can be caused by any event or thought that makes people feel worried, angry or nervous [27, 41, 42].
Overall, this study showed that poor sleep quality was the most significant predictor of all three of depression, anxiety, and stress for the remote workers. The association between mental health problems and sleep quality may be related not only to changes in the daily routines of employees but also concerns about the COVID-19 pandemic itself. Overtime, increased workload, spending more time on household chores and childcare, irregular working hours can play a role in sleep disturbances for the remote workers. Contrary to previous views that sleep disorders are the result of many psychiatric disorders, new views suggest that sleep disorders may play an important role in the development and maintenance of various mental health problems [43]. A meta-analysis by Baglioni et al. [44] indicated that people who suffered from sleep problems had a two-fold risk of developing depression over those who did not suffer from sleep problems. It has been suggested that acute 
Table 4

Comparison of factors related to changes in work and home life by sex

\begin{tabular}{|c|c|c|c|}
\hline \multirow[t]{2}{*}{ Variables } & & \multicolumn{2}{|c|}{ Sex } \\
\hline & & Female $(n=205)$ & Male $(n=254)$ \\
\hline \multirow[t]{3}{*}{ Changes in time spent on household chores } & mean $\pm s d$ & $6.35 \pm 2.09$ & $5.79 \pm 1.49$ \\
\hline & $\mathrm{t}$ & \multicolumn{2}{|c|}{-3.316} \\
\hline & $\mathrm{p}$ & \multicolumn{2}{|c|}{0.001} \\
\hline \multirow[t]{3}{*}{ Changes in time spent on childcare } & mean $\pm \mathrm{sd}$ & $6.12 \pm 1.89$ & $6.18 \pm 1.59$ \\
\hline & $\mathrm{t}$ & \multirow{2}{*}{\multicolumn{2}{|c|}{$\begin{array}{r}0.334 \\
0.739\end{array}$}} \\
\hline & $\mathrm{p}$ & & \\
\hline \multirow[t]{3}{*}{ Changes in daily working hours } & mean $\pm s d$ & $5.60 \pm 2.66$ & $4.95 \pm 2.36$ \\
\hline & $\mathrm{t}$ & \multicolumn{2}{|c|}{-2.759} \\
\hline & $\mathrm{p}$ & \multicolumn{2}{|c|}{0.006} \\
\hline \multirow[t]{3}{*}{ Changes in workload } & mean $\pm \mathrm{sd}$ & $3.49 \pm 0.88$ & $3.27 \pm 0.91$ \\
\hline & $\mathrm{t}$ & \multicolumn{2}{|c|}{-2.522} \\
\hline & $\mathrm{p}$ & \multicolumn{2}{|c|}{0.012} \\
\hline \multirow[t]{3}{*}{ Distractions while working } & mean $\pm \mathrm{sd}$ & $2.82 \pm 1.18$ & $2.53 \pm 1.14$ \\
\hline & $\mathrm{t}$ & \multicolumn{2}{|c|}{-2.609} \\
\hline & $\mathrm{p}$ & \multicolumn{2}{|c|}{0.009} \\
\hline \multirow[t]{3}{*}{ Trouble focusing at work } & mean $\pm \mathrm{sd}$ & $2.91 \pm 1.12$ & $2.80 \pm 1.16$ \\
\hline & $\mathrm{t}$ & \multirow{2}{*}{\multicolumn{2}{|c|}{$\begin{array}{c}-0.974 \\
0.331\end{array}$}} \\
\hline & $\mathrm{p}$ & & \\
\hline \multirow[t]{3}{*}{ Workplace loneliness } & mean $\pm \mathrm{sd}$ & $2.76 \pm 0.76$ & $2.88 \pm 0.83$ \\
\hline & $\mathrm{t}$ & \multicolumn{2}{|c|}{1.664} \\
\hline & $\mathrm{p}$ & & \\
\hline
\end{tabular}

sleep deprivation can elevate the risk for anxiety and distress [45]. Poor sleep quality can make it more difficult to deal with even low-grade stress. Previous studies reported that there were data showing the impact of stressful events on mental health had been stronger for individuals with poor sleep quality than individuals with better sleep quality [46, 47]. Therefore, sleep disturbances can make individuals more vulnerable by preventing the interest and energy required to cope with the harsh conditions of WFH.

We suggested that gender inequality could emerge considering changes in time spent on dealing with household chores and childcare among heterosexual dual-career parents during WFH. In this study, it was determined that the time women spent on household chores increased more than men. Contrary to expectations, one of the surprising findings of the study was the extent to which the working hours and workload of females increased more than males. This finding can be explained by the fact that the boundaries between work and home are more blurred, as women working from home respond more to family demands. Another possible explanation is that differences in time use may cause differences in women's and men's perceptions of working times. Even women's leisure is often spent in the presence of children and more often interrupted by household chores and childcare $[48,49]$. In other words, this may be due to increased responsibility and a heavier workload. Another important finding from this study was that women experienced more frequent distractions due to external factors such as children playing, pets, and neighbors making noise. This situation could be explained by the fact that children were more present in the working area of mothers at the time of work and caused more work interruptions [37]. This study also found that women working remotely were more likely to report feeling depressed, anxious, and stressed than men working remotely. These findings seem likely to be due to changes in overtime and increased workload. Therefore, it is predicted that WFH can induce gender inequality in many dimensions.

One of the main differences between working from the office and WFH is the lack of face-to-face interaction with colleagues and teammates. Managing workplace loneliness during these unprecedented times is undoubtedly a challenge. One of the remarkable findings of this study concerns the strong association between workplace loneliness and stress, which confirmed previous studies [50, 51]. Workplace loneliness occurs when interpersonal relationships that individuals expect in the workplace and the actual relationships are different, and individuals' inability to compensate for this difference [52]. Another important finding was that workplace 
Table 5

DASS-21 questionnaire sub-dimensions by multiple linear regression analysis

\begin{tabular}{|c|c|c|c|c|c|c|c|}
\hline & \multirow[t]{2}{*}{ Variables } & \multicolumn{2}{|l|}{ Depression } & \multicolumn{2}{|l|}{ Anxiety } & \multicolumn{2}{|l|}{ Stress } \\
\hline & & $\beta(95.0 \% \mathrm{CI}$ for $\mathrm{B})$ & $p$ & $\beta(95.0 \% \mathrm{CI}$ for $\mathrm{B})$ & $p$ & $\beta(95.0 \% \mathrm{CI}$ for $\mathrm{B})$ & $p$ \\
\hline \multirow[t]{5}{*}{ Sociodemographic characteristics } & $\operatorname{Sex}^{\mathrm{a}}$ & $0.137(0.487,1.770)$ & 0.001 & $0.097(0.090,1.204)$ & 0.023 & $0.155(0.640,1.993)$ & $<0.001$ \\
\hline & Age & $0.003(-0.054,0.058)$ & 0.943 & $-0.040(-0.068,0.029)$ & 0.432 & $-0.039(-0.083,0.035)$ & 0.426 \\
\hline & Educational status ${ }^{\mathrm{b}}$ & $-0.020(-0.829,0.480)$ & 0.601 & $-0.070(-1.073,0.064)$ & 0.082 & $-0.025(-0.924,0.458)$ & 0.508 \\
\hline & Working organizations ${ }^{\mathrm{c}}$ & $0.049(-0.308,1.425)$ & 0.206 & $0.009(-0.667,0.839)$ & 0.822 & $0.033(-0.524,1.305)$ & 0.402 \\
\hline & Having a child ${ }^{\mathrm{d}}$ & $0.046(-1.304,0.552)$ & 0.426 & $0.050(-0.475,1.137)$ & 0.421 & $0.076(-0.333,1.625)$ & 0.195 \\
\hline \multirow{10}{*}{$\begin{array}{l}\text { Changes in work and home life } \\
\text { during working from home }\end{array}$} & Changes in time spent on household chores & $0.050(-0.066,0.294)$ & 0.215 & $0.047(-0.070,0.242)$ & 0.281 & $0.008(-0.171,0.208)$ & 0.847 \\
\hline & Changes in time spent on childcare & $-0.046(-0.331,0.112)$ & 0.332 & $-0.082(-0.350,0.035)$ & 0.110 & $-0.025(-0.295,0.173)$ & 0.609 \\
\hline & Changes in daily working hours & $-0.016(-0.173,0.122)$ & 0.732 & $0.002(-0.125,0.132)$ & 0.960 & $0.032(-0.102,0.210)$ & 0.497 \\
\hline & Changes in workload & $0.085(-0.026,0.802)$ & 0.066 & $0.117(0.070,0.789)$ & 0.019 & $0.068(-0.121,0.752)$ & 0.156 \\
\hline & Control over working hours & $0.094(0.086,1.010)$ & 0.020 & $0.065(-0.096,0.706)$ & 0.136 & $0.079(-0.013,0.962)$ & 0.056 \\
\hline & Distractions while working & $0.066(-0.108,0.571)$ & 0.181 & $0.082(-0.062,0.528)$ & 0.122 & $0.088(-0.041,0.677)$ & 0.082 \\
\hline & Trouble focusing at work & $0.138(0.195,0.796)$ & $<0.001$ & $0.080(-0.029,0.493)$ & 0.082 & $0.165(0.291,0.925)$ & $<0.001$ \\
\hline & Current financial state & $-0.003(-0.165,0.176)$ & 0.948 & $-0.035(-0.201,0.095)$ & 0.485 & $-0.034(-0.244,0.115)$ & 0.482 \\
\hline & Financial concern & $-0.090(-0.340,-0.007)$ & 0.060 & $-0.054(-0.231,0.070)$ & 0.293 & $-0.100(-0.375,-0.009)$ & 0.040 \\
\hline & Workplace loneliness & $-0.133(-1.071,-0.283)$ & 0.001 & $-0.061(-0.595,0.089)$ & 0.147 & $-0.095(-0.915,-0.083)$ & 0.019 \\
\hline \multirow[t]{6}{*}{ Body wellness } & Jenkins Sleep Scale score & $0.378(0.253,0.388)$ & $<0.001$ & $0.373(0.197,0.314)$ & $<0.001$ & $0.324(0.211,0.354)$ & $<0.001$ \\
\hline & Leisure-Time Exercise Questionnaire score & $-0.094(-0.034,-0.004)$ & 0.012 & $-0.032(-0.018,0.008)$ & 0.428 & $-0.006(-0.017,0.014)$ & 0.877 \\
\hline & $\mathrm{F}$ & 16.759 & & 11.215 & & 14.687 & \\
\hline & $\mathrm{p}$ & $<0.001$ & & $<0.001$ & & $<0.001$ & \\
\hline & & 0.40 & & 0.31 & & 0.37 & \\
\hline & mean $\pm \mathrm{SD}$ & $5.81 \pm 4.11$ & & $3.93 \pm 3.32$ & & $6.62 \pm 4.22$ & \\
\hline
\end{tabular}

${ }^{\mathrm{a}}$ Reference group $=$ male; ${ }^{\mathrm{b}}$ Reference group $=$ university graduation; ${ }^{\mathrm{c}}$ Reference group $=$ public sector; ${ }^{\mathrm{d}}$ Reference group $=$ no child . 
loneliness predicted depression for remote workers. People spend most of their waking hours, usually with teammates and colleagues because of the nature of their jobs. Social interactions are basic psychological requirements for human well-being. Therefore, when people work from home, that aspect of their social life disappears. The results of this study supported the view that perceived workplace loneliness led to depression [53].

Trouble focusing at work can be challenging for first-time remote workers. An interesting finding from this study was that trouble focusing at work had been predictive of depression and stress. Trouble focusing can reduce work productivity. Fried et al. [54] suggested that difficulties with concentration and focus could lead to the emergence of depression by making working life and personal relationships more challenging.

The COVID-19 pandemic has caused serious disruption in the economies of many countries. The shrinking economies cause both an increase in unemployment rates and most of the workers to worry about their financial situation [55]. It has been demonstrated that economic vulnerability is associated with a strong risk of stress and mental health problems $[38,56,57]$. This study found that financial concern was an important factor in predicting stress. The fact that the financial concern affects stress levels more than the current financial situation can be attributed to both uncertain duration of the pandemic period and hopelessness about economic recovery.

WFH and prolonged restrictions can lead to decreased opportunities for outdoor exercise [58, 59]. Excessive screen time causes a decrease in physical activity. The current study found that low physical activity increased susceptibility to depression for remote workers. This finding broadly supported other studies in this area linking lower levels of physical activity and sedentary lifestyle with depression $[60,61]$. Regular exercise may help ease depression by releasing feel-good endorphins and serotonin that can enhance the sense of well-being. Exercise alleviates depressive symptoms such as low self-esteem and social withdrawal $[62,63]$.

\section{Conclusions}

This study has identified the predictors of depression, anxiety, and stress for first-time remote workers during the COVID-19 pandemic and pointed out that gender inequality might increase further during
WFH. The study contributes to our understanding that some conditions about WFH may associate with mental health more than others. This study highlights the urgent need for psychological support and counseling for remote workers with elevated depression, anxiety, and stress symptoms during the current pandemic or any quarantine implementation. Further research in this field would be of great help in understanding the impact of WFH on mental health and gender differences.

\section{Limitations}

This research had some limitations. First, because the current study was a cross-sectional study, only the relationship could be implied, not causation. Second was the snowball sampling strategy, which could limit the representativeness of study participants. Third, the study was conducted using a web-based self-report rather than a direct face-to-face interview. However, since random sampling is difficult to achieve in a situation like the COVID-19 pandemic, web-based sampling is a preferred alternative [64]. Lastly, re-sharing the survey link could lead to potential bias with high uniformity. Although the findings of the study should be interpreted carefully due to the limitations mentioned above, the results may shed light on future studies as it is the first study in this field.

\section{Acknowledgments}

The authors are grateful to all remote workers who participated in this study.

\section{Conflict of interest}

The authors declare no possible conflicts of interest with respect to the research, authorship, and/or publication of this article.

\section{Funding}

The authors received no financial support for the research, authorship and/or publication of this article. 


\section{References}

[1] Mukhtar S. Psychological health during the coronavirus disease 2019 pandemic outbreak. Int J Soc Psychiatry. 2020; 66(5):512-16.

[2] Acemoglu D, Chernozhukov V, Werning I, D Whinston M. "Optimal Targeted Lockdowns in a Multi-Group SIR Model'NBER Working Papers27102, National Bureau of Economic Research, Inc. 2020.

[3] Alon TM, Doepke M, Olmstead-Rumsey J, Tertilt M. The impact of COVID-19 on gender equality. NBER Work. Pap. Ser. Published online 2020:0898-2937.

[4] Toniolo-Barrios M, Pitt L. Mindfulness and the challenges of working from home in times of crisis. Bus Horiz. 2021; 64(2):189-97.

[5] Tavares AI. Telework and health effects review. Int J Healthc. 2017;3(2):30.

[6] Arlinghaus A, Nachreiner F. Health effects of supplemental work from home in the European Union. Chronobiol Int. 2014;31(10):1100-7.

[7] Noonan M, Glass J. The hard truth about telecommuting. Monthly Lab Rev. 2012;135(38).

[8] Messenger J, Oscar V, Gschwind L, Boehmer S, Vermeylen G, Wilkens M. Working anytime, anywhere: The effects on the world of work. Publications Office of the European Union, Luxembourg, and the International Labour Office, Geneva. 2017.

[9] Firoozabadi A, Uitdewilligen S, Zijlstra FRH. Solving problems or seeing troubles? A day-level study on the consequences of thinking about work on recovery and well-being, and the moderating role of self-regulation. Eur J Work Org Psychol. 2018;27(5):629-41.

[10] Sonnentag S, Fritz C. The Recovery Experience Questionnaire: development and validation of a measure for assessing recuperation and unwinding from work. J Occup Health Psychol. 2007;12(3):204-21.

[11] Sonnentag S, Binnewies C, Mojza EJ. Staying well and engaged when demands are high: the role of psychological detachment. J Appl Psychol. 2010;95(5):965-76.

[12] Moreno-Jiménez B, Mayo M, Sanz-Vergel AI, Geurts S, Rodríguez-Muñoz A, Garrosa E. Effects of work-family conflict on employees' well-being: the moderating role of recovery strategies. J Occup Health Psychol. 2009;14(4): 427-40.

[13] Wang B, Liu Y, Qian J, Parker SK. Achieving effective remote working during the COVID-19 pandemic: A work design perspective. Appl Psychol. 2020;70(1):16-59.

[14] Shiovitz-Ezra S, Leitsch SA. The role of social relationships in predicting loneliness: The national social life, health, and aging project. Soc Work Res. 2010;34(3):157-67.

[15] Morin CM, Carrier J. The acute effects of the COVID-19 pandemic on insomnia and psychological symptoms. Sleep Med. 2021;77:346-47.

[16] Casagrande M, Favieri F, Tambelli R, Forte G. The enemy who sealed the world: effects quarantine due to the COVID19 on sleep quality, anxiety, and psychological distress in the Italian population. Sleep Med. 2020;75:12-20.

[17] Li D-J, Ko N-Y, Chen Y-L, Wang P-W, Chang Y-P, Yen C-F, Lu W-H. COVID-19-related factors associated with sleep disturbance and suicidal thoughts among the Taiwanese public: A Facebook survey. Int J Environ Res Public Health. 2020;17(12):4479.

[18] Altena E, Baglioni C, Espie CA, Ellis J, Gavriloff D, Holzinger B, Schlarb A, Frase L, Jernelöv S, Riemann D. Dealing with sleep problems during home confinement due to the COVID-19 outbreak: Practical recommendations from a task force of the European CBT-I Academy. J Sleep Res. 2020;29(4):e13052.

[19] Morin CM, Carrier J, Bastien C, Godbout R, Canadian Sleep and Circadian Network. Sleep and circadian rhythm in response to the COVID-19 pandemic. Can J Public Health. 2020;111(5):654-7.

[20] Celis-Morales CA, Lyall DM, Steell L, Gray SR, IIidromiti $\mathrm{S}$, Anderson J, Mackay DF, Welsh P, Yates T, Pell J. Associations of discretionary screen time with mortality, cardiovascular disease and cancer are attenuated by strength, fitness and physical activity: findings from the UK Biobank study. BMC Med. 2018;16(1). doi:10.1186/ s12916-018-1063-1.

[21] Stamatakis E, Gale J, Bauman A, Ekelund U, Hamer M, Ding D. Sitting time, physical activity, and risk of mortality in adults. J Am Coll Cardiol. 2019;73(16):2062-72.

[22] Blair-Loy M. Competing Devotions: Career and Family among Women Executives. Harvard University Press; 2009.

[23] Hays S. The Cultural Contradictions of Motherhood. Yale University Press; 1998.

[24] Thistle S. From Marriage to the Market: The Transformation of Women's Lives and Work. Univ of California Press; 2006.

[25] Prasad K, Mangipudi MR. A General Linear Model Approach: Development Of Psychological Well-Being, Remote Working, Employee Engagement, Job Satisfaction, Scales, Data Analysis And Reporting Concerning To Information Technology Sector. J. Contemp. Issues bus. gov. 2021;27(1):1006-35.

[26] Etikan I, Alkassim R, Abubakar S. Comparision of snowball sampling and sequential sampling technique. Biom biostat int j. 2016;3(1).

[27] Lovibond PF, Lovibond SH. The structure of negative emotional states: comparison of the Depression Anxiety Stress Scales (DASS) with the Beck Depression and Anxiety Inventories. Behav Res Ther. 1995;33(3):335-43.

[28] Akin A, Çetın B. The Depression Anxiety and Stress Scale (DASS): The study of Validity and Reliability. Educational Sciences: Theory \& Practice. 2007;7(1).

[29] Yıldırım A, Boysan M, Kefeli MC. Psychometric properties of the Turkish version of the Depression Anxiety Stress Scale-21 (DASS-21). Br J Guid Counc. 2018;46(5):582-95.

[30] Jenkins CD, Stanton BA, Niemcryk SJ, Rose RM. A scale for the estimation of sleep problems in clinical research. $\mathrm{J}$ Clin Epidemiol. 1988;41(4):313-21.

[31] Tibubos AN, Zenger M, Schmalbach B, Beutel ME, Brähler E. Measurement invariance, validation and normative data of the Jenkins Sleep Scale-4 (JSS-4) in the German general population across the life span. J Psychosom Res. 2020;130(109933):109933.

[32] Duruöz MT, Erdem D, Gencer K, Ulutatar F, Baklacıŏlu HŞ. Validity and reliability of the Turkish version of the Jenkins Sleep Scale in psoriatic arthritis. Rheumatol Int. 2018;38(2):261-5.

[33] Godin G, Shephard RJ. A simple method to assess exercise behavior in the community. Can J Appl Sport Sci. 1985;10(3):141-6.

[34] Lapa TY, Certel Z, Kaplan K, Yağar G. Serbest zaman egzersiz anketinin adolesan çağı öğrencileri için geçerlik güvenirlik çalışması. Eğitim ve Öğretim Araştırmaları Dergisi. 2016;5:1-9.

[35] Tabachnick B, Fidell L. Using Multivariate Statistics (6th Edition). MA. Pearson/Allyn \& Bacon; 2013.

[36] Russo D, Hanel PH, Altnickel S, Berkel N. Predictors of Well-being and Productivity among Software Professionals 
during the COVID-19 Pandemic-A Longitudinal Study. Published online 2020.

[37] Lyttelton T, Zang E, Musick K. Gender differences in telecommuting and implications for inequality at home and work. SSRN Electron J. Published online 2020. doi: 10.2139/ssrn.3645561

[38] Hertz-Palmor N, Moore TM, Gothelf D, DiDomenico GE, Dekel I, Greenberg DM, Brown LA, Matalon N, Visoki E, White LK, Himes MH, Liftshitz-Schwartz M, Gross R, Gur RC, Gur RE, Pessach IM, Barzilay R. Association among income loss, financial strain and depressive symptoms during COVID-19: evidence from two longitudinal studies. medRxiv. Published online 2020. doi:10.1101/ 2020.09.15.20195339

[39] Singh G. Changes in work culture and workplace due to COVID19 crisis. PsyArXiv. Published online 2020. doi:10.31234/osf.io/htjx5

[40] Liu RX, Kuang J, Gong Q, Hou XL. Principal component regression analysis with SPSS. Comput Methods Programs Biomed. 2003;71(2):141-7.

[41] George LK. Social Factors, Depression, and Aging. In: Handbook of Aging and the Social Sciences. Elsevier; 2011:149-62.

[42] Beck AT, Beamesderfer A. Assessment of Depression: The Depression Inventory. Psychological Measurements in Psychopharmacology. Karger Publishers; 1974.

[43] Scott AJ, Webb TL, Rowse G. Does improving sleep lead to better mental health? A protocol for a meta-analytic review of randomised controlled trials. BMJ Open. 2017;7(9): e016873.

[44] Baglioni C, Battagliese G, Feige B, Spiegelhalder K, Nissen C, Voderholzer U, Lombardo C, Riemann D. Insomnia as a predictor of depression: a meta-analytic evaluation of longitudinal epidemiological studies. J Affect Disord. 2011;135(1-3):10-9.

[45] Babson KA, Trainor CD, Feldner MT, Blumenthal H. A test of the effects of acute sleep deprivation on general and specific self-reported anxiety and depressive symptoms: an experimental extension. J Behav Ther Exp Psychiatry. 2010;41(3):297-303.

[46] Leggett A, Burgard S, Zivin K. The impact of sleep disturbance on the association between stressful life events and depressive symptoms. J Gerontol B Psychol Sci Soc Sci. 2016;71(1):118-28.

[47] Li Y, Gu S, Wang Z, Li H, Xu X, Zhu H, Deng S, Ma X, Feng G, Wang F, Huang JH. Relationship between stressful life events and sleep quality: Rumination as a mediator and resilience as a moderator. Front Psychiatry. 2019;10:348.

[48] Bittman M, Wajcman J. The rush hour: The character of leisure time and gender equity. Soc Forces. 2000;79(1): 165-89.

[49] Craig L, Mullan K. Parental leisure time: A gender comparison in five countries. Soc Polit. 2013;20(3):329-57.

[50] Stephenson LE, Bauer SC. The role of isolation in predicting new principals' burnout. Int j Educ Policy Leadersh. 2010;5(9). doi:10.22230/ijepl.2010v5n9a275.

[51] Weinert C, Maier C, Laumer S. Why Are Teleworkers Stressed? An Empirical Analysis of the Causes of Telework-Enabled Stress. Universität Osnabrück FB Wirtschaftswissenschaften, Organisation u. Wirtschaftsinformatik; 2015.
[52] Wright SL. Organizational climate, social support and loneliness in the workplace. In: Research on Emotion in Organizations. Emerald (MCB UP); 2007:123-42.

[53] Hawkley LC, Capitanio JP. Perceived social isolation, evolutionary fitness and health outcomes: a lifespan approach. Philos Trans R Soc Lond B Biol Sci. 2015;370(1669): 20140114.

[54] Fried EI, Nesse RM. The impact of individual depressive symptoms on impairment of psychosocial functioning. PLoS One. 2014;9(2):e90311.

[55] Wilson JM, Lee J, Fitzgerald HN, Oosterhoff B, Sevi B, Shook NJ. Job insecurity and financial concern during the COVID-19 pandemic are associated with worse mental health. J Occup Environ Med. 2020;62(9):686-91.

[56] Codagnone C, Bogliacino F, Gómez C, Charris R, Montealegre F, Liva G, Lupiáñez-Villanueva F, Folkvord F, Veltri GA. Assessing concerns for the economic consequence of the COVID-19 response and mental health problems associated with economic vulnerability and negative economic shock in Italy, Spain, and the United Kingdom. PLoS One. 2020;15(10):e0240876.

[57] Aranda MP, Lincoln KD. Financial strain, negative interaction, coping styles, and mental health among low-income Latinos. Race Soc Probl. 2011;3(4):280-97.

[58] Sato K, Sakata R, Murayama C, Yamaguchi M, Matsuoka Y, Kondo N. Working from home and lifestyle changes associated with risk of depression during the COVID-19 pandemic: An observational study of health app (CALO mama) users. SSRN Electron J. Published online 2020. doi: $10.2139 / \mathrm{ssrn} .3661202$

[59] Chen P, Mao L, Nassis GP, Harmer P, Ainsworth BE, Li F. Wuhan coronavirus (2019-nCoV): The need to maintain regular physical activity while taking precautions. J. Sport Health Sci. 2020;9(2).

[60] Stubbs B, Vancampfort D, Hallgren M, Firth J, Veronese N, Solmi M, Brand S, Cordes J, Malchow B, Gerber M, Schmitt A, Correll CU;De Hert M, Gaughran F, Schneider F, Kinnafick F, Falkai P, Möller H-J, Kahl KG. EPA guidance on physical activity as a treatment for severe mental illness: a meta-review of the evidence and Position Statement from the European Psychiatric Association (EPA), supported by the International Organization of Physical Therapists in Mental Health (IOPTMH). Eur Psychiatry. 2018;54:124-44.

[61] Dunn AL, Trivedi MH, Kampert JB, Clark CG, Chambliss HO. Exercise treatment for depression: efficacy and dose response. Am J Prev Med. 2005;28(1):1-8.

[62] Peluso MAM, Guerra de Andrade LHS. Physical activity and mental health: the association between exercise and mood. Clinics (Sao Paulo). 2005;60(1):61-70.

[63] Dadvand SS, Daryanoosh F. The effect of a period of aerobic training on blood levels of serotonin and endorphin and decreasing depression in addicted women to drug. Daneshvar Medicine: Basic and Clinical Research Journal. 2017;25(2):49-56.

[64] Boni RBD. Web surveys in the time of COVID-19. Cad Saude Publica. 2020;36(7):e00155820. 